Revista

Ibero-Americana

de Estratégıa
DOI: http://dx.doi.org/10.5585/riae.v11i2.1914

Organização: Comitê Científico Interinstitucional

Editor Científico: Benny Kramer Costa

Avaliação: Double Blind Review pelo SEER/OJS

Revisão: Gramatical, normativa e de formatação

ESTRATÉGIA DE INTERNACIONALIZAÇÃO DE EMPRESAS BRASILEIRAS DE CONSTRUÇÃO PESADA: REFLEXÕES SOBRE A TRAJETÓRIA E RESULTADOS

INTERNATIONALIZATION STRATEGY OF BRAZILIAN HEAVY CONSTRUCTION: REFLECTIONS ON THE HISTORY AND RESULTS

ESTRATEGIA DE INTERNACIONALIZACIÓN DE LA CONSTRUCCIÓN PESADA BRASILEÑA: REFLEXIONES SOBRE LA HISTORIA Y LOS RESULTADOS

Flavia Luciane Scherer

Doutora em Centro de Pós-Graduação e Pesquisas em Administração pela Universidade Federal de Minas Gerais - UFMG

Professora da Universidade Federal de Santa Maria - UFSM

E-mail: flaviascherer@globo.com (Brasil) 
Estratégia de Internacionalização de Empresas Brasileiras de Construção Pesada: Reflexões sobre a Trajetória e Resultados

\title{
ESTRATÉGIA DE INTERNACIONALIZAÇÃO DE EMPRESAS BRASILEIRAS DE CONSTRUÇÃO PESADA: REFLEXÕES SOBRE A TRAJETÓRIA E RESULTADOS
}

\section{RESUMO}

Considerando o fato de que a internacionalização é um fenômeno em franca expansão, o artigo objetiva descrever o processo de internacionalização de empresas brasileiras do setor de construção pesada que tenham internacionalizado suas atividades por meio da realização de investimento direto no exterior (IDE). O foco está na compreensão das trajetórias adotadas, no entendimento das escolhas feitas, e na identificação dos resultados obtidos por tais empresas, experientes em mercados internacionais. A realização da pesquisa empírica em empresas do segmento da construção pesada considerou a necessidade de ampliar o escopo de estudos relativos à internacionalização de empresas de serviço. Quanto à trajetória adotada para internacionalização, a análise dos quatro casos evidenciou semelhanças. Para minimizar o desconhecimento relativo às condições de mercado, as empresas trabalham, em regra, com parceiros locais. Quanto às escolhas estratégicas e resultados decorrentes, os casos mostraram que a manutenção da atividade externa obedeceu a critérios outros, além da lucratividade. A manutenção de operações externas também foi explicada em função da necessidade de atualização constante. Diferentes estágios de internacionalização foram identificados nas empresas estudas.

Palavras-chave: Internacionalização; Construção Pesada; Trajetória.

\section{INTERNATIONALIZATION STRATEGY OF BRAZILIAN HEAVY CONSTRUCTION: REFLECTIONS ON THE HISTORY AND RESULTS}

\begin{abstract}
Considering the fact that internationalization is a booming phenomenon, the paper aims to describe the process of internationalization of Brazilian companies in the heavy construction sector which have internationalized their activities through the execution of foreign direct investment (FDI). The focus is to understand the trajectories adopted in understanding the choices made, and the identification of the results obtained by these companies, experienced in international markets. Performing empirical research in business segment of heavy construction felt the need to broaden the scope of studies related to the internationalization of service firms. About the internationalization path adopted, the analysis of four cases showed similarities. To minimize the ignorance concerning market conditions, companies work normally with local partners. Concerning strategic choices and outcomes arising, the cases showed that the maintenance of external activity followed other criteria in addition to profitability. Maintaining external operations also been explained in terms of the need for constant updating. Different stages of internationalization were identified in the companies studied.
\end{abstract}

Keywords: Internationalization; Heavy Construction; Path.

Revista Ibero-Americana de Estratégia - RIAE, São Paulo, v. 11, n. 2, p. 281-307, mai./ago. 2012. 
Flavia Luciane Scherer

\section{ESTRATEGIA DE INTERNACIONALIZACIÓN DE LA CONSTRUCCIÓN PESADA BRASILEÑA: REFLEXIONES SOBRE LA HISTORIA Y LOS RESULTADOS}

\section{RESUMEN}

Teniendo en cuenta el hecho de que la internacionalización es un fenómeno en auge, el artículo tiene como objetivo describir el proceso de internacionalización de las empresas brasileñas en el sector de la construcción pesada, que han internacionalizado sus actividades a través de la ejecución de la inversión extranjera directa (IED). La atención se centra en la comprensión de las trayectorias adoptadas en la comprensión de las decisiones tomadas, y la identificación de los resultados obtenidos por estas empresas, con experiencia en los mercados internacionales. Realización de la investigación empírica en el segmento de negocio de la construcción pesada sintió la necesidad de ampliar el alcance de los estudios relacionados con la internacionalización de las empresas de servicios. En cuanto a la ruta de internacionalización adoptada para el análisis de cuatro casos mostraron similitudes. Para minimizar la ignorancia acerca de las condiciones del mercado, las empresas trabajan normalmente con socios locales. En cuanto a las decisiones estratégicas y los resultados que surjan, los casos mostraron que el mantenimiento de la actividad externa siguió a los otros criterios además de la rentabilidad. El mantenimiento de las operaciones externas también se ha explicado en términos de la necesidad de actualización constante. Diferentes etapas de internacionalización fueron identificados en las empresas estudiadas.

Palabras-clave: Internacionalización; Construcción Pesada; Trayectoria.

Revista Ibero-Americana de Estratégia - RIAE, São Paulo, v. 11, n. 2, p. 281-307, mai./ago. 2012. 
Estratégia de Internacionalização de Empresas Brasileiras de Construção Pesada: Reflexões sobre a Trajetória e Resultados

\section{INTRODUÇÃO}

A elevada turbulência que caracteriza as relações econômicas mundiais tem suscitado o crescente interesse sobre o tema da internacionalização de empresas, o qual é rico em suas nuanças e pode ser estudado sob distintas orientações. Neste artigo, adotou-se uma orientação oriunda do campo de estudos de negócios internacionais.

Considerando o fato de que a internacionalização é um fenômeno em franca expansão, pretende-se descrever o processo de internacionalização de empresas brasileiras do setor de construção pesada que tenham internacionalizado suas atividades por meio da realização de investimento direto no exterior (IDE). O foco está na compreensão das trajetórias adotadas, no entendimento das escolhas feitas, e na identificação dos resultados obtidos por tais empresas, experientes em mercados internacionais. A realização da pesquisa empírica em empresas do segmento da construção pesada considerou a necessidade de ampliar o escopo de estudos relativos à internacionalização de empresas de serviço. A este respeito, Patterson e Cicic (1995) manifestaram preocupação com o fato de que, apesar da crescente internacionalização da indústria de serviço, pesquisas sobre o setor eram raras. Segundo eles, eram relativamente poucos os estudos que lidavam explicitamente com serviços, sejam eles do tipo profissional ou acompanhados por bens tangíveis.

\section{A INTERNACIONALIZAÇÃO COMO UM PROCESSO ESTRATÉGICO}

No desenvolvimento do presente estudo está-se adotando a noção de que a ida de uma empresa ao mercado externo é resultado de uma decisão de caráter estratégico. Processos deliberados, tanto quanto emergentes, são considerados. Autores como Mata e Portugal (2004), Dunning (1996), Li (1995), Melin (1992), Johanson e Vahlne (1990) e Douglas e Craig (1989) fazem, com maior ou menor grau de destaque, menção às questões estratégicas subjacentes à ida de empresas ao mercado externo. De forma bastante clara, Melin (1992) argumenta que a internacionalização deve ser entendida - e estudada - sob a forma de processo estratégico. Para esse autor, internacionalização é uma dimensão maior do contínuo processo estratégico da maioria das empresas. Sua proposta considera que as fronteiras entre teoria organizacional, gestão estratégica e gestão internacional são fluidas e indistintas. Para ele, a dimensão "internacionalização" deveria ser tratada como um foco empírico e não formar a base para o campo teórico de sua própria gestão (MELIN, 1992, p.114). 
Na visão de Johanson e Vahlne (1990, p. 22), "processos de internacionalização são o resultado de uma mescla de pensamento estratégico, ação estratégica, desenvolvimentos emergentes, oportunidade e necessidade". Ainda que tais aspectos não tenham sido abordados na proposição original do modelo Uppsala, principal obra desses autores, em publicações posteriores passaram a admitir sua importância no processo.

Em Dunning (1996), também se encontra referência ao fato de que as três vantagens determinantes da internacionalização (descritas no paradigma eclético) não fornecem elementos suficientes para explicar, na totalidade, diferenças identificadas na trajetória de internacionalização de empresas de um mesmo setor econômico. Vê-se a menção implícita às questões estratégicas quando o autor advoga o uso da teoria da administração estratégica, somada às abordagens econômicas, para explicar o surgimento e crescimento de multinacionais. Em outro contexto, Dunning (1988, p. 25) expressa o desejo de perceber um gradual entrelaçamento entre os enfoques do economista, do analista de negócios e do teórico organizacional para a compreensão da produção internacional.

Assumir que a entrada em mercados externos é uma decisão estratégica implica considerar que fatores anteriores (gatilhos) impulsionaram tal decisão. Aspectos como tempo, sequiência e mudança são críticos quando se trata de processos de internacionalização. Por considerar tais argumentos como críticos, Melin (1992) propõe que a internacionalização - o processo de ampliar o envolvimento em operações internacionais através de fronteiras - seja estudada como uma dimensão maior do processo estratégico permanente, que é encontrado na grande maioria das empresas. Além disso, é o processo estratégico que determina o contínuo desenvolvimento e as mudanças na empresa internacional em termos de seu escopo, idéia de negócio, orientação para a ação, princípios organizacionais, natureza do trabalho gerencial, valores dominantes e normas convergentes.

Para Melin (1992), o campo necessita de estudos que capturem longas épocas e, mesmo, histórias biográficas acerca de todo o desenvolvimento de uma firma. É considerado problemático, portanto, o fato de a maioria dos estudos publicados ter, como foco de pesquisa, companhias em fases iniciais de internacionalização. A perspectiva de que a internacionalização é uma dimensão maior de um processo estratégico permanente leva a algumas decorrências na abordagem empírica. Sob esse aspecto, esse autor afirma que é imperativo observar que processos de internacionalização são caracterizados por um alto grau de complexidade, variabilidade e heterogeneidade, os quais, tomados em conjunto, requerem pesquisa holística e enfoques longitudinais.

Mantendo a mesma linha de argumentação, Douglas e Craig (1989) acreditam que a internacionalização ocorre sob a forma de um processo incremental, o qual diz respeito aos movimentos de uma firma por meio de sucessivas fases, cada uma formada por novos desafios estratégicos e prioridades 
Estratégia de Internacionalização de Empresas Brasileiras de Construção Pesada: Reflexões sobre a Trajetória e Resultados

decisórias. Emerge dessa concepção a premissa de que os imperativos estratégicos e as questões-chave com os quais uma empresa se depara variarão em dependência ao grau de experiência e natureza das operações em mercados internacionais. Em conformidade com tais autores, a dinâmica do desenvolvimento estratégico global é mais bem explicada pela compreensão de um número de parâmetros-chave cuja natureza e impacto dependerão da fase do processo de internacionalização no qual se encontra a empresa em foco.

A FIG. 1 esquematiza esse processo, mostrando que em cada fase gatilhos detonarão uma nova etapa, estimulando a geração de um novo ímpeto estratégico. Nela, está representado o processo de envolvimento com mercados internacionais por meio do uso de alguns construtos:

- Gatilhos. Podem ser internos e externos e se aplicam às situações que impulsionam uma empresa a se mover de uma fase para a próxima. Como exemplos de fatores externos, os autores citam fatores ambientais, tendências na indústria e pressões competitivas; e como exemplos de fatores internos: volume de vendas, lucratividade e iniciativas gerenciais.

- Impulso estratégico. Determina a direção a ser seguida e define a arena de competição, assim como as prioridades estratégicas das empresas.

- Alavancas estratégicas. As alavancas estratégicas ajudam a fixar definições da direção dos esforços da empresa e a estabelecer prioridades de decisão e de investimentos em cada etapa sucessiva da internacionalização.

- Decisões estratégicas. O impulso estratégico da firma e as alavancas para a internacionalização, em conjunto, determinam decisões estratégicas que são chave em cada etapa de internacionalização.

Revista Ibero-Americana de Estratégia - RIAE, São Paulo, v. 11, n. 2, p. 281-307, mai./ago. 2012. 
Figura 1 - A dinâmica do desenvolvimento da estratégia global.

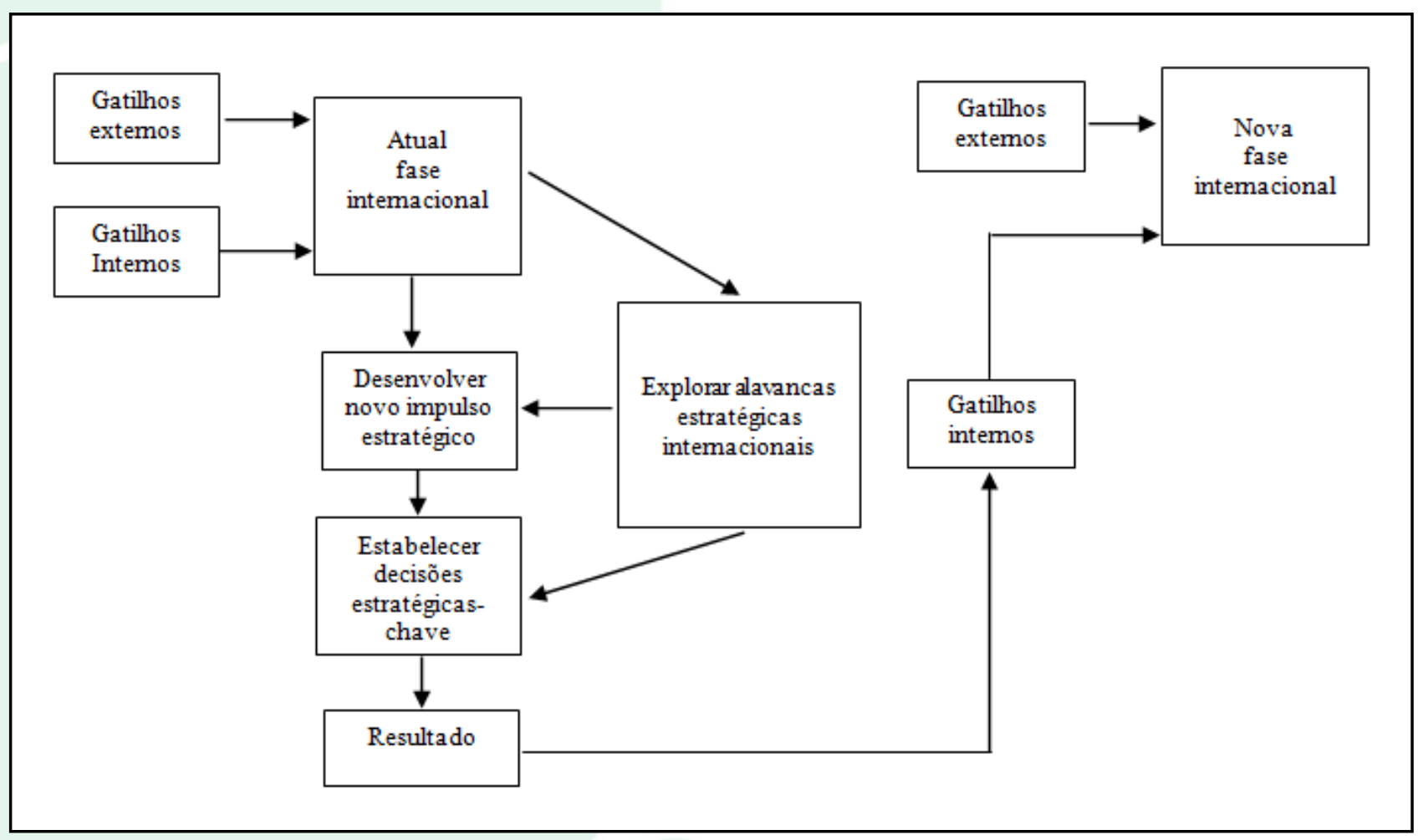

Fonte: Douglas e Craig (1989).

Considerando tais parâmetros em mercados internacionais, o impulso estratégico, as decisões-chave e as alavancas evoluem a partir do grau de experiências, do estágio e do envolvimento em operações estrangeiras. As fases do processo de internacionalização, para esses autores, são três: entrada inicial; expansão no mercado local (país-a-país); e racionalização global, as quais são antecedidas por uma fase prévia, chamada de "pré-internacionalização".

- Etapa pré-internacionalização. Corresponde à fase anterior à entrada em mercados internacionais, quando o mercado doméstico é o ponto focal para o desenvolvimento estratégico e define as fronteiras das operações.

- Etapa1 - Entrada inicial no mercado internacional. Este passo é essencialmente crucial, uma vez que um movimento equivocado nesse estágio pode resultar na retirada dos investimentos em mercados internacionais. Li (1995) explica que a escolha de uma estratégia apropriada de entrada é um determinante crítico do provável sucesso das operações estrangeiras. Segundo ele, estudos realizados sugerem que as escolhas relativas à entrada afetarão significativamente o desempenho e a sobrevivência de subsidiárias estrangeiras.

Revista Ibero-Americana de Estratégia - RIAE, São Paulo, v. 11, n. 2, p. 281-307, mai./ago. 2012. 
Estratégia de Internacionalização de Empresas Brasileiras de Construção Pesada: Reflexões sobre a Trajetória e Resultados

Nesta etapa, os esforços da empresa são dirigidos para a identificação das oportunidades de mercado - no exterior - mais atrativas para seus produtos e serviços já existentes. A empresa procura minimizar ao extremo a necessidade de adaptação de produtos ou estratégias de marketing.

- Etapa 2 - Expansão no mercado local. Ocorre quando a empresa sente que tem condições de procurar novas direções para o crescimento e expansão. A força motriz subjacente a esta etapa, é a expansão em países nos quais a empresa penetrou na fase inicial, ao invés da entrada em mercados adicionais. Seus autores explicam que a ênfase se desloca da decisão de exportar a estratégia doméstica aos países de entrada inicial para a de desenvolver estratégia em uma base de país-a-país.

- Etapa 3 - Racionalização global. Nesta etapa final da internacionalização, a empresa se move em direção à adoção de uma orientação global no desenvolvimento e implementação da estratégia. Douglas e Craig (1989) expõem que a atenção foca a melhoria da eficiência de operações mundiais e o desenvolvimento de mecanismos para melhorar a coordenação de operações transnacionais e a integração da estratégia entre países. A orientação nacional desaparece, e mercados são vistos como um conjunto de entidades inter-relacionadas e interdependentes, as quais estão se tornando crescentemente integradas e interligadas pelo mundo afora.

O modelo de Douglas e Craig (1989) trabalha dentro de um quadro evolucionário, apresentando estágios pelos quais uma empresa passa em seu processo de internacionalização, mas seus autores adicionam o componente estratégico no modelo que propõem. Eles explicam que a cada etapa novos gatilhos surgirão, e esses, caso se manifestem e sejam julgados oportunos pelos gestores, impulsionarão o desenvolvimento de uma nova etapa, de crescente envolvimento internacional. Assim, as etapas não assumem um comportamento seqüencial, que ocorrerá independentemente de que decisões estratégicas nessa direção sejam tomadas ou não.

Com base no modelo evolucionário de Douglas e Craig (1989), Kotabe e Helsen (1998) propuseram que o envolvimento das empresas com mercados externos, sob a perspectiva de marketing internacional, passa por fases que saem de uma orientação de marketing doméstico e chegam ao chamado marketing global. A FIG. 2 ilustra a seqüência proposta por estes autores.

Revista Ibero-Americana de Estratégia - RIAE, São Paulo, v. 11, n. 2, p. 281-307, mai./ago. 2012. 
Figura 2 - Evolução de marketing global.

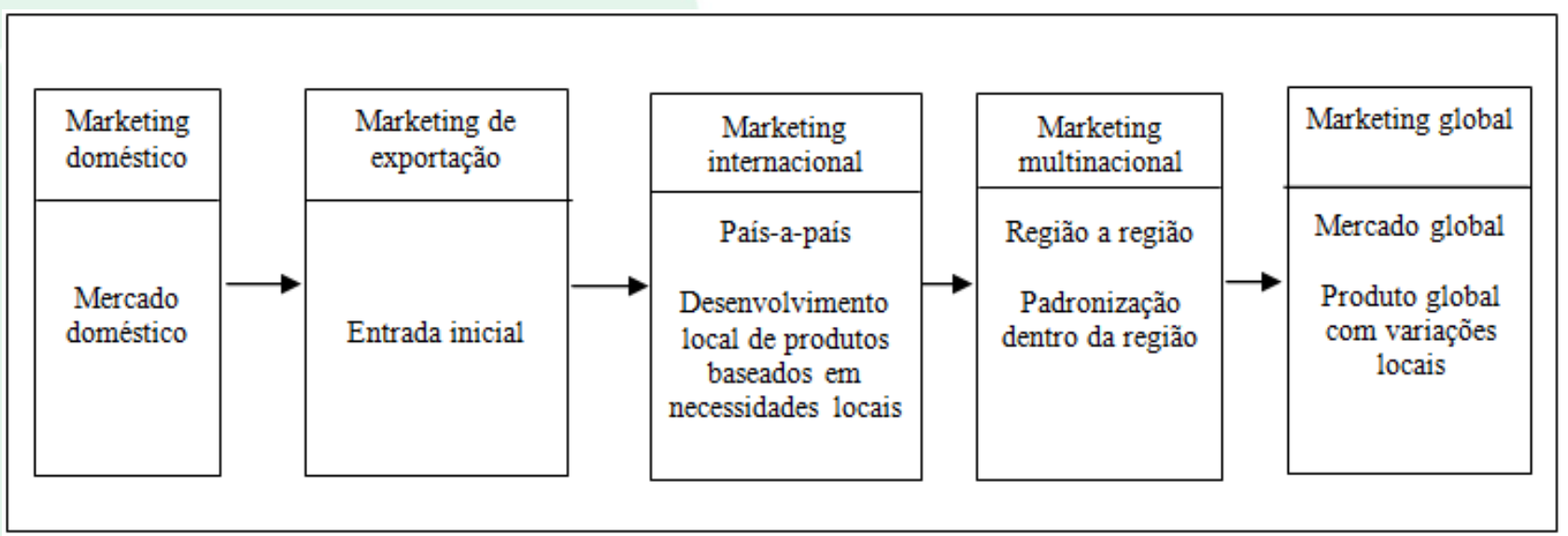

Fonte: KOTABE e HELSEN, 1998, p. 10.

A orientação global, sob a perspectiva desses autores, representa o ápice do envolvimento com mercados externos. É caracterizada por uma abordagem geocêntrica, que observa a necessidade de adaptações locais. Em comparação à proposta de Douglas e Craig (1989), Kotabe e Helsen (1998) avançam pela inclusão de mais uma fase no processo de evolução e por diferenciar as orientações dos tipos internacional e multinacional, algo que não ficou explicitado na proposta original. Logo, as bases de avaliação passam a ser "país-a-país", "regiões" e "globo".

\section{MÉTODO}

Em relação ao tipo de pesquisa desenvolvido, os procedimentos realizados foram classificados como pesquisa conclusiva descritiva (MALHOTRA, 2001; MATTAR, 1997). A coleta dos dados foi feita sob uma orientação qualitativa. Sobre a estratégia de pesquisa, foi realizado um estudo de casos múltiplos em quatro empresas brasileiras, de grande porte, que atuam no setor de construção pesada: Andrade Gutierrez, Norberto Odebrecht, Mendes Júnior e Queiroz Galvão.

Foram buscados dados em fontes primárias e secundárias. Dados primários foram obtidos através de entrevistas semi-estruturadas. Dados secundários foram obtidos por meio de relatórios e/ou publicações das empresas, conteúdo dos web sites das construtoras e, no caso da Mendes Júnior e da Norberto Odebrecht, também foi utilizado material extraído de livros publicados por seus presidentes. Além disso, foram buscados dados em jornais e periódicos especializados e em pesquisas previamente realizadas.

Revista Ibero-Americana de Estratégia - RIAE, São Paulo, v. 11, n. 2, p. 281-307, mai./ago. 2012. 
Estratégia de Internacionalização de Empresas Brasileiras de Construção Pesada: Reflexões sobre a Trajetória e Resultados

Para o tratamento dos dados, optou-se pela utilização da análise de conteúdo, por entender-se que é um método apropriado quando o fenômeno a ser observado é a comunicação, e não um comportamento ou objetos físicos (MALHOTRA, 2001). Bardin (2004) esclarece que a partir de um conjunto de técnicas, o pesquisador "trabalha a palavra, quer dizer, a prática da língua realizada por emissores identificáveis" (BARDIN, 2004, p. 38). As unidades de observação (QUADRO 1) compreenderam profissionais de alta direção com experiência e conhecimento na área de internacionalização.

\begin{tabular}{|c|c|}
\hline EMPRESA & CARGO DO ENTREVISTADO \\
\hline $\begin{array}{l}\text { ANDRADE GUTIERREZ } \\
\text { (MG) }\end{array}$ & $\begin{array}{l}\text { Diretor Internacional } \\
\text { Diretor do Núcleo Jurídico } \\
\text { Ex-Diretor do Núcleo Jurídico }\end{array}$ \\
\hline QUEIROZ GALVÃO (RJ) & $\begin{array}{l}\text { Diretor de Suporte à Gestão e Tecnologia } \\
\text { Diretor Internacional }\end{array}$ \\
\hline MENDES JÚNIOR (MG) & $\begin{array}{l}\text { Presidente } \\
\text { Diretor Executivo Tecnologia - Engenharia (ex-diretor adjunto da área internacional) } \\
\text { Membro do Conselho Administrativo }\end{array}$ \\
\hline $\begin{array}{l}\text { NORBERTO ODEBRECHT } \\
\text { (RJ) }\end{array}$ & $\begin{array}{l}\text { Ex-presidente e membro do Conselho de Administração } \\
\text { Diretor de Relaçõos Institucionais }\end{array}$ \\
\hline
\end{tabular}

Quadro 1 - Unidades de Observação.

\section{RESULTADOS}

Para orientação geral, vale ressaltar que a indústria da construção pesada apresenta peculiaridades relativas à atividade internacional. Diferentemente de outros segmentos de negócios, neste a entrada em um mercado ocorre de forma mais intensa, por se tratar de prestação de serviços que não podem, obviamente, ser entregues por intermédio de mera exportação.

Logo, as etapas de envolvimento com o mercado externo descritas por Johanson e Vahlne (1990), não se aplicam diretamente ao setor em particular, pois supõem que a fase 1 representa atividades de exportação irregulares, e a fase 2 é a de exportação por intermédio de representantes independentes. Tais

Revista Ibero-Americana de Estratégia - RIAE, São Paulo, v. 11, n. 2, p. 281-307, mai./ago. 2012. 
situações não poderiam ser utilizadas por empresas de engenharia e construção. A entrada, por força legal, dá-se pelo estabelecimento de subsidiária (fase 3), juntamente com a fabricação no exterior, chamada de "fase 4" pelos mesmos autores. O modelo proposto pela escola de Uppsala, por conseguinte, parece mais adequado à descrição de processos de internacionalização de empresas produtoras de bens.

- Construtora Andrade Gutierrez. A internacionalização teve início efetivo em 1984, com o começo das obras para a construção de uma rodovia no Congo, África. A decisão de entrar no mercado internacional foi motivada pela necessidade de buscar alternativas diante da crise econômica pela qual o Brasil passava, ocasionando refreamento dos investimentos públicos, e promovendo sérias consequências à empresa.

Em entrevista, o diretor internacional explicou que o ano de 1983 "foi o ápice da crise negra que a empresa viveu". Nesse ano, a construtora demitiu 53 engenheiros, pela primeira vez em sua história, para continuar operando. "Era preciso buscar outros caminhos, e o exterior foi a saída", afirmou o diretor. A fala do entrevistado remete à perspectiva de Lewin, Long e Carroll (1999), segundo os quais em períodos de elevada turbulência é esperado que dirigentes intensifiquem e diversifiquem atividades de prospecção. A incerteza torna os gestores mais pró-ativos na busca por novas áreas de segurança para o negócio. Foi esse o caso da Andrade Gutierrez.

Sob essa ótica, a empresa transformou as condições adversas do mercado interno em estímulo à conquista de mercados internacionais. Nos relatos presentes em seu histórico, a empresa expõe que, além do mercado internacional, sua estratégia de sobrevivência à crise levou à diversificação dos negócios. É explicado, então, que durante a década de 1980,

[...] o desaquecimento da economia exigiu de nós uma nova postura. [...]. Decidimos, além disso, que era hora de conquistar o mercado externo. O projeto de estréia foi uma estrada no Congo, África (ANDRADE GUTIERREZ, 2004, p. 2).

A internacionalização é posta como uma das estratégias encontradas para resolver os problemas enfrentados. A partir da obra realizada no Congo, a empresa expandiu-se por vários países e continentes. Segundo o diretor internacional, "tivemos muita sorte no primeiro contrato, ganhou-se muito dinheiro". A obtenção de bons resultados em sua primeira empreitada internacional fez com que a empresa ficasse otimista em relação ao mercado externo. Além do Congo, Bolívia e Equador foram os primeiros países a serem trabalhados pela Andrade Gutierrez. As três experiências iniciais foram muito boas em termos de preços e de resultados. Nas três obras a construtora contou com financiamento do governo brasileiro, e os 
Estratégia de Internacionalização de Empresas Brasileiras de Construção Pesada: Reflexões sobre a Trajetória e Resultados

"resultados obtidos fizeram com que os patrões acreditassem no potencial", explicou o diretor internacional. Para ele, tais contratos foram importantes porque levaram a empresa a "criar cultura e exposição internacional".

Em relação à forma de entrada no mercado externo, o entrevistado explicou que isso varia muito, de país-a-país. Em alguns, a empresa atua sozinha e em outros por intermédio de parceiros locais. As exigências feitas pelo cliente, seja ele público ou privado, definem a melhor forma de presença no mercado externo. A tendência é de que a maioria dos clientes exija o uso de consórcios - muitas vezes com empresas locais, para estimular a indústria nacional - ou que façam opção por contratos de empreitada global. De modo geral, a Andrade Gutierrez opta por abrir escritórios ou sucursais naqueles países em que está trabalhando ou que pretende vir a trabalhar. A estrutura é pequena e utiliza o mínimo possível de brasileiros. A esse respeito, o diretor internacional contou que, no passado, a empresa levava para o exterior grande número de funcionários e uma estrutura pesada que lhes desse suporte. No Congo, a Andrade Gutierrez construiu 155 casas para seus funcionários e famílias, construiu instalações de suporte para abrigar granja de frangos, abatedouro, escola e dois hospitais, dentre outras facilidades. A idéia prevalecente na época era a de minimizar o desconforto de estar em um país estrangeiro. A empresa tentava reproduzir no exterior as condições de vida no Brasil. De acordo com o diretor entrevistado, isto não faz mais sentido. Segundo ele, apenas quando a empresa ingressa em um novo país é que utiliza uma equipe maior de brasileiros. A decisão de minimizar a presença de brasileiros no exterior considerou que a expatriação é um processo complicado e sujeito a muitos problemas. A experiência da empresa em suas primeiras empreitadas externas levou-a a este aprendizado.

No Congo, a criação da superestrutura procurava amenizar os desconfortos trazidos pela estadia em um país estranho. No entanto, o custo para manter tal estrutura de apoio era muito alto e refletia na competitividade das empresas que adotavam essa estratégia. Além disso, perceberam outro problema: os funcionários criavam guetos e não se relacionavam com a sociedade local. Surgiram daí conflitos entre brasileiros pelo convívio extremo, além de rejeição da população local, causada pelo isolacionismo praticado. Com tais problemas de ordem social, a empresa logo viu que era necessário desenvolver programas de treinamento para que brasileiros fossem preparados para a vida fora do Brasil. Surgiu, portanto, nova orientação. A perspectiva passou a ser a de que quanto mais integrado ao país, melhor seria a vida e melhores seriam os negócios para a empresa.

A expansão no mercado internacional foi intensa nos anos 90. Foi no começo da década que, para consolidar a presença no mercado Europeu, optou pela compra da Zagope, empresa portuguesa de médio porte, tradicional e que estava enfrentando problemas de natureza financeira. A compra da Zagope fez com

Revista Ibero-Americana de Estratégia - RIAE, São Paulo, v. 11, n. 2, p. 281-307, mai./ago. 2012. 
que a Andrade Gutierrez se adequasse à legislação da Comunidade Européia, que protegia seu mercado em relação a empresas não européias. Assim, foi adquirido 100\% do controle da Zagope, e a empresa pôde atuar no mercado europeu. Recentemente tal empresa passou a ser responsável pela conquista dos mercados internacionais, exceto a América Latina (que passou a ser o foco da construtora Andrade Gutierrez).

Em relação à atuação internacional, o diretor declarou acreditar que a empresa está consolidada, sobretudo a partir da compra da Zagope (1989-1990). Apesar de já ter tido resultados ruins, os últimos 15 anos têm sido marcados por operações crescentes e bons resultados. Segundo ele, as estratégias adotadas pelo Conselho de Administração em relação à atuação internacional - como a compra da Zagope, o foco em menor número de países e, mais recentemente, a definição da América Latina como mercado internacional da Andrade Gutierrez - foram decisivas para que os resultados da construtora fossem crescentemente positivos.

Em meados da década de 1990, a empresa cresceu muito, chegando a mais de 50 contratos simultâneos no exterior. Estava atuando em pouco mais de 20 países, sem que tivesse ocorrido prévia estruturação das equipes, o que aponta para equívocos na solução para o problema administrativo. De acordo com o diretor internacional, em decorrência do acúmulo de contratos e da falta de estrutura para a gestão dos mesmos, inúmeras falhas comprometeram a realização dos trabalhos e refletiram nos resultados negativos auferidos pela empresa. Além disso, aconteceram muitas situações de não-cumprimento de contratos, o que revelou erros no processo de escolha de oportunidades, pois a avaliação havia desconsiderado questões importantes, relativas a risco político e capacidade de solvência dos contratantes. Entretanto, a empresa "honrou seus compromissos, mesmo tendo prejuízos", segundo o diretor internacional, "para não prejudicar a imagem de credibilidade que queria ter".

Ainda que negativo, tal quadro não motivou o abandono do mercado internacional. Ao contrário, fez com que a empresa avaliasse seu negócio externo em uma perspectiva estratégica de longo prazo, de forma a direcionar os processos futuros. Dessa forma, no final dos anos 90 a empresa redirecionou sua atuação, optando por permanecer naqueles países em que o entrosamento local havia sido melhor e os resultados mais satisfatórios.

Tal avaliação integrou um processo mais amplo, de planejamento estratégico, a partir do qual a empresa fez um mapeamento de países com potencial de negócio e os colocou em ordem de interesse. A base de comparação foram os indicadores relativos à estabilidade política, ao planejamento do país em obras de infra-estrutura, às linhas de financiamento, e à estrutura econômica e social, dentre outros. Considerando tal ranking, a empresa elegeu países de interesse e criou estruturas locais para dar suporte aos executivos designados para prospecção de oportunidades negócios.

Revista Ibero-Americana de Estratégia - RIAE, São Paulo, v. 11, n. 2, p. 281-307, mai./ago. 2012. 
Estratégia de Internacionalização de Empresas Brasileiras de Construção Pesada: Reflexões sobre a Trajetória e Resultados

A permanência no mercado externo foi uma opção de natureza estratégica, porque representou para a empresa a oportunidade manter sua estrutura e seguir crescendo, haja vista que o mercado doméstico continuava mostrando sinais de retração. Ficar apenas no Brasil representaria optar por voltar a ser pequena e perder expertise, algo considerado inadequado pela administração do Grupo. Outra influência na decisão é a crença generalizada de que investimentos em infra-estrutura voltarão a ser feitos no Brasil em pouco tempo (espera-se que o Programa de Aceleração do Crescimento do Governo Federal crie oportunidades de negócio) e quando isso acontecer o esperado é que somente empresas que se mantiveram atualizadas, tecnológica e operacionalmente, poderão disputar essas oportunidades. É o caso da Andrade Gutierrez.

A opção da Andrade Gutierrez pelo mercado internacional pode ser considerada como próxima do que foi chamado de fase 2 - Expansão no mercado local -, de Douglas e Craig (1989). Neste caso, a empresa procurou desenvolver estratégia em uma base de país-a-país. Dos gatilhos que levam a esta fase, o desejo de promover iniciativas gerenciais locais e a motivação e a necessidade de responder às iniciativas competitivas locais em preço parecem ser as que melhor se adaptam à situação da empresa.

No tocante ao futuro, o entrevistado aponta que a formação de um novo ambiente no Brasil com a retomada de investimentos em infra-estrutura, da intensidade como ocorrido na década de setenta, poderia motivar a presença da construtora apenas no Brasil, desde que ela estivesse bem estruturada para manter o "quinhão" que tinham à época. Caso essa situação viesse a se configurar, a participação da empresa no mercado internacional poderia ser feita somente pela Zagope. Para ele, essa previsão de cenário seria viável porque "trabalhar no Brasil é muito mais fácil, seguro e tranqüilo". No entanto, destacou ser esta apenas a sua avaliação pessoal.

- Construtora Norberto Odebrecht. Iniciou a internacionalização de suas atividades em 1979, com a construção da hidrelétrica Charcani V, no Peru, e as obras de desvio do Rio Maule, para a construção da hidrelétrica Colbún-Machicura, no Chile. Nos anos de 1980, entrou no mercado africano, com a construção de outra hidrelétrica, desta vez em Angola, e, desde então tem ampliado continuamente sua presença em mercados internacionais. Segundo relato do expresidente, a opção foi iniciar a atividade internacional pela América Latina, onde se esperava encontrar maior afinidade cultural e, mesmo, de língua.

A decisão de ingressar no mercado internacional foi tomada como resposta à diminuição dos investimentos em infra-estrutura que caracterizaram a década de 1970. O esgotamento do "milagre brasileiro" fez com que a empresa estudasse três hipóteses: diversificar; ir para o exterior; ou fortalecer a 
qualificação em engenharia no Brasil. "Em vez de um, a Organização opta pelos três movimentos estratégicos" (ODEBRECHT, 2004).

Fortalecemos nossa presença em Engenharia e Construção, adquirindo novas competências com a compra da CBPO e da Tenenge; iniciamos nossa atuação internacional, conquistando contratos no Peru e no Chile; e realizamos nosso primeiro investimento em petroquímica, adquirindo um terço do capital da CPC, empresa do Pólo de Camaçari (ODEBRECHT, 2004).

Em 1988, a Odebrecht resolveu atuar no mercado europeu. Pelas restrições legais (já relatadas no caso Andrade Gutierrez), adquiriu a empresa portuguesa José Bento Pedroso \& Filhos, rebatizada de Bento Pedroso Construções (BPC), por meio da qual passou a atuar naquele país. No início dos anos 90, o foco internacional deslocou-se para o Primeiro Mundo. “Já em 1991, torna-se a primeira empresa brasileira a vencer uma concorrência pública nos Estados Unidos" (ODEBRECHT, 2004). No mesmo ano, passou a atuar na Inglaterra, país no qual também precisou adquirir uma empresa local (SLP Engineering), para atender à exigência legal de que a participação de empresas nacionais fosse intensa. Ao abandonar o segmento de petróleo, a Odebrecht desfez-se da SLP.

Para ingressar no mercado americano, a empresa estabeleceu uma joint venture com uma empresa de Miami durante os dois primeiros anos de atuação naquele país. Essa aliança produziu vantagens à empresa pela incorporação de conhecimentos e o conseqüente domínio das estruturas de mercado, capacidades e habilidades que a qualificaram a atuar sozinha. A forma de ingresso em cada mercado internacional, portanto, dependeu da análise do contexto. De acordo com o ex-presidente, "não há uma regra. A empresa busca sempre a maneira mais adequada à legislação local e às oportunidades”. A única conduta que a empresa adota é a de sempre trabalhar com parceiros locais para melhor entendimento de como serão os processos de concorrência ou licitação. Eventualmente, pode fazer parcerias com empresas brasileiras ou, mesmo, com empresas locais. A escolha do parceiro, em cada país, irá depender do que ele poderá aportar em termos de conhecimento de mercado, domínio da estrutura sociocultural, domínio tecnológico, etc.

A expansão da Odebrecht continuou pelos anos seguintes, chegando à Ásia, Alemanha e América Central. Em 2003, abriu escritório nos Emirados Árabes Unidos, dando início à atuação no Oriente Médio. A escolha de países para trabalhar é feita com base na expectativa de longo prazo de atuação. Ou seja, "toda análise para entrar em um país deve considerar que é para ficar, no mínimo, cinqüenta anos. Consideramos que é para permanecer em definitivo". Mas nem todas as decisões foram acertadas. Em alguns casos, como na Alemanha e na Malásia, a empresa não obteve êxito em sua prospecção de negócios, apesar da orientação ser a de "não sair do Brasil para dar uma dentada e voltar".

Além disso, para trabalhar em algum país, a empresa avalia, inicialmente, se possui profissionais preparados para isso. "Mais que tudo, é preciso ter o homem", afirmou o ex-presidente. "O homem" refere- 
Estratégia de Internacionalização de Empresas Brasileiras de Construção Pesada: Reflexões sobre a Trajetória e Resultados

se ao profissional educado de acordo com a filosofia da Tecnologia Empresarial Odebrecht, com tempo de casa suficiente para já ter aprendido a decidir. O profissional precisa saber tomar decisões que sejam voltadas aos interesses dos acionistas e dos clientes. "É um conflito permanente de interesses, e ele precisa saber lidar com estas situações”. Por isso, o requisito prévio é a delegação planejada, por meio da qual o profissional (empresário-parceiro) aprenderá a tomar decisões.

A entrada nos EUA obedeceu à estratégia de fortalecimento da competitividade da empresa. Para tanto, avaliaram que era preciso trabalhar em um país de Primeiro Mundo com altos níveis de competição. A escolha pelos EUA objetivou “desasnar" (deixar de ser asno) a empresa. De acordo com o diretor de Relações Institucionais, "no estágio em que a empresa estava, era fundamental ter certeza absoluta de que era competitiva para fazer qualquer coisa". Atuar no mercado americano, na opinião do diretor, trouxe maior qualificação às equipes, pois é um ambiente que proporciona menores rendimentos, exige maior sofisticação tecnológica e apresenta complexidade nas operações financeiras. Fica evidente, portanto, que a internacionalização é avaliada não só em termos de desempenho econômico, mas também a partir de outros resultados favoráveis, como o acréscimo na qualificação dos funcionários da empresa.

Sob a ótica da consolidação no mercado externo, na Odebrecht a manutenção das atividades internacionais e a contínua expansão em novos mercados ou, mesmo, em mercados atuais têm ocorrido desde as primeiras obras no exterior. O rumo da empresa de "sobreviver, crescer e perpetuar" igualmente ajuda a explicar, na opinião do diretor de relações institucionais, a participação crescente no exterior. "É a estratégia pela qual a empresa perpetua suas atividades". Somente será possível "crescer e perpetuar" a partir da busca permanente de novas oportunidades.

Em termos da consolidação no mercado internacional, o diretor de relações institucionais afirmou que ela poderia ser explicada por duas razões: TEO e pessoas. Segundo ele, foi a filosofia de trabalho, por intermédio das pessoas que a praticaram, que levou a empresa ao lugar de destaque que hoje ocupa no cenário mundial. Além dessas considerações, esse diretor fez questão de destacar que a consolidação também é resultado de uma decisão de caráter político-estratégico. Ao decidir ingressar em mercados internacionais, a empresa encarou a escolha como definitiva e passou a vê-la no contexto de "sobreviver, crescer e perpetuar". "A orientação foi sempre esta. A perspectiva de futuro sempre foi fundamental para podermos estimular nossos profissionais", afirmou o diretor.

A análise dos dados mostrou que a Construtora Norberto Odebrecht é, dentre as construtoras pesquisadas, a que alcançou maior envolvimento com atividades internacionais e que o enfoque básico da gestão assumiu uma perspectiva de orientação global, e não mais internacional ou multinacional.

Revista Ibero-Americana de Estratégia - RIAE, São Paulo, v. 11, n. 2, p. 281-307, mai./ago. 2012. 
- Construtora Queiroz Galvão. Dentre as construtoras pesquisadas, a Queiroz Galvão é a que possui menos experiência internacional. No mercado externo, a primeira obra executada pela empresa foi uma barragem, no Uruguai, em 1984. Na época, segundo o diretor da Área Internacional, a empresa atuou como se fosse uma obra no Brasil, sem se adaptar às condições locais. O resultado foi negativo, especialmente do ponto de vista financeiro. A Queiroz Galvão perdeu muito dinheiro e interrompeu as atividades internacionais, até que, em 1994, firmou contrato na Bolívia.

A ida para mercados externos foi motivada por duas razões principais, segundo relatou o diretor. A primeira pode ser explicada pelo processo de abertura de mercados, que mostrou à Queiroz Galvão que precisava estar estruturada para trabalhar com outras multinacionais e que era necessário conhecer outras culturas. Para o entrevistado, a empresa percebeu que o mercado nacional poderia ser dominado por grandes multinacionais e que não detinha know how para enfrentar este tipo ambiente de negócios.

Assim, penetrar no mercado externo seria uma alternativa para, dentre outras coisas, mostrar ao mercado que a empresa também tinha competência de gestão de projetos internacionais. Sua postura tem como orientação subjacente a emissão de sinais aos concorrentes, conforme explicaram Heil, Day e Reibstein (1999). Ou seja, a empresa objetivou tornar explícita sua postura competitiva diante das concorrentes internacionais.

A segunda razão é encontrada na necessidade de manter o nível de faturamento, em baixa pela situação do mercado brasileiro que apresentava uma redução de investimento em obras de infra-estrutura. Sobre este aspecto, o diretor de Suporte à Gestão e Tecnologia afirmou que "não dá para sobreviver só de pintar muro de cemitério". Ou seja, uma empresa do porte da Queiroz Galvão não poderia ficar à mercê de pequenas obras, principalmente porque, conforme ele, a empresa não é competitiva neste segmento por não trabalhar com o menor preço do mercado (que é o critério de escolha em licitações). Por isso, precisou buscar obras de infra-estrutura que fossem de maior envergadura.

$\mathrm{Na}$ avaliação dos fatores que impulsionaram a empresa ao mercado externo, a análise mostrou que, seguindo Douglas e Craig (1989), os motivos principais foram a busca de oportunidades, o desejo de manterse atualizada e a saturação do mercado doméstico.

O diretor internacional foi contratado pela Queiroz Galvão em 1992, quando teve início a estruturação da área internacional da empresa. Anteriormente, ele havia trabalhado por dez anos na Mendes Júnior, sendo sete no Iraque. Para estruturar a área internacional, a construtora contava com a experiência que ele tinha em mercados externos. Ao buscar um profissional oriundo da construtora que havia sido símbolo da internacionalização do setor, a Queiroz talvez estivesse procurando naquela empresa um modelo. 
Estratégia de Internacionalização de Empresas Brasileiras de Construção Pesada: Reflexões sobre a Trajetória e Resultados

Conforme DiMaggio e Powell (1991), modelos podem ser difundidos indiretamente, pela transferência ou contratação de empregados.

Na Bolívia, a primeira obra teve início em 1994. Foi realizada após a estruturação da área internacional, durante a qual a América Latina foi definida como alvo preferencial da construtora. Os resultados obtidos desta vez foram positivos, e a empresa passou a manter presença contínua naquele país desde então.

A definição do mercado em torno dos países latinos decorreu da busca por proximidade físicogeográfica e cultural. A empresa procurava por mercados e obras nos quais conseguisse acumular aprendizado internacional sem correr muitos riscos. O diretor explicou em sua entrevista que a prospecção de mercado foi orientada para obras de menor porte, da ordem de 20 milhões de dólares, algo mais comum em países do Terceiro Mundo. Segundo ele, a empresa julgou que seria melhor correr o risco de errar em uma obra de menor valor do que em um projeto de 300 milhões de dólares, por exemplo. Sua fala confirma o foco da Queiroz Galvão em segurança financeira.

Considerando que a definição do domínio de mercado foi realizada a partir da contratação de um diretor com larga experiência na área internacional, podem-se reconhecer nessa decisão indícios de que a experiência negativa da referida construtora deixou marcas em seu perfil gerencial. Naquele país, os contratos firmados eram da ordem de centenas de milhares de dólares e o não-recebimento dos valores devidos afetou a história da empresa. Trabalhar com contratos de pequeno valor, por certo, diminui as chances de que em caso de não-pagamento a empresa enfrente riscos relativos à sua capacidade de sobrevivência.

A proximidade cultural foi um fator significativo na escolha dos mercados-alvo, pois a empresa avaliou que seria melhor minimizar a necessidade de adaptação. As vantagens proporcionadas pela proximidade de língua foram consideradas importantes, pois entendiam que era difícil estruturar uma equipe com domínio da língua inglesa, por exemplo. "Engenheiro que fale inglês é figura rara. Técnico então nem pensar. E a gente não queria iniciar tendo dificuldades de comunicação".

Sobre as formas de entrada em outros países, o diretor da Área Internacional explicou que a empresa procura fazer consórcios com empresas locais, as quais são chamadas de "parceiros locais". Esses parceiros costumam ser empresas menores, que buscam apoio tecnológico e financeiro junto a uma empresa maior, como é o caso da Queiroz. A presença de um sócio local é necessária para que a empresa tenha um aporte em termos de conhecimento, domínio de cultura, recrutamento de pessoal, legislação, tributos, procedimentos, etc.

Revista Ibero-Americana de Estratégia - RIAE, São Paulo, v. 11, n. 2, p. 281-307, mai./ago. 2012. 
À época da entrevista, a empresa executava obras na Bolívia, no Peru e no Chile. Segundo seu diretor, a longo prazo, a empresa pretendia expandir suas atividades para países da África e do Oriente Médio, além dos Estados Unidos. Em relação à expansão, ele considerava que "seguimos um processo mais conservador". Ou seja, a empresa só partirá em busca de alternativas mais ousadas quando avaliar que os riscos compensam a empreitada e quando sentir que tem domínio pleno da atividade externa. Apesar dessa aparente insegurança diante de outros mercados, o entrevistado considera que a Queiroz Galvão consolidou sua presença na América Latina, pois tem obtido envolvimento crescente mediante a conquista de novos contratos. Segundo ele, "as metas têm sido batidas".

Ao avaliar a atividade em mercados externos, o diretor da Área Internacional ponderou que o desempenho é positivo em termos de qualificação e experiência dos profissionais. "Hoje, a Queiroz ocupou um espaço no mercado. É considerada como parte do negócio de construção internacional”. Em termos financeiros, no entanto, a empresa ainda não conseguiu obter lucratividade, pois está pagando pelas primeiras incursões que foram negativas. A expectativa é a de que resultados financeiros virão. "É uma questão de tempo".

Para o diretor de Suporte à Gestão e Tecnologia, o resultado da atividade internacional é positivo sob a perspectiva de experiência organizacional, amadurecimento, aperfeiçoamento cultural e formação de base para o futuro da empresa. "Insisto: a Queiroz Galvão acredita que, com conhecimento e capacidade de trabalho conseguirá bons negócios no exterior. O mercado existe e é positivo. Pode ser a base para crescimento futuro". O modo como os entrevistados responderam ao serem questionados sobre resultados mostrou que a empresa buscou, por meio da estratégia de internacionalização, resultados outros além do lucro.

- Construtora Mendes Júnior. Seu processo de internacionalização iniciou-se em 1969, com as obras da usina hidrelétrica de Santa Isabel, na Bolívia. Em 1975, a empresa assinou o maior contrato de toda a África na época: uma rodovia de 600 quilômetros, na Mauritânia.

Talvez fosse possível afirmar que a empresa, ao ser criada, já tinha vocação para a internacionalização. Segundo seu presidente, “a Mendes nasceu do seguinte princípio: estar entre as melhores, não só no Brasil, mas também no exterior”. Em sua entrevista, ele relatou que durante a década de 1950 observava que apenas firmas estrangeiras executam obras complexas de engenharia. Foi aí que teria surgido a ideia de construir uma empresa tão boa quanto as melhores.

Revista Ibero-Americana de Estratégia - RIAE, São Paulo, v. 11, n. 2, p. 281-307, mai./ago. 2012. 
Estratégia de Internacionalização de Empresas Brasileiras de Construção Pesada: Reflexões sobre a Trajetória e Resultados

A ida para o mercado externo foi motivada pelo entendimento de que uma empresa do porte da Mendes Júnior deveria diversificar seu risco. "Desde o início das atividades do grupo, a decisão de se expandir internacionalmente era estratégica” (MENDES e ATTUCH, 2004, p. 118). Já nos anos 60,

[...] o consultor norte-americano James Libby aconselhou a Mendes Júnior a recrutar engenheiros com experiência internacional, por duas razões básicas: em primeiro lugar, o mercado brasileiro de engenharia continuava disputado por grandes companhias estrangeiras; em segundo, a internacionalização seria uma estratégia adequada para uma empresa do porte da Mendes, como forma de diversificação de riscos. Não era conveniente depender apenas do desempenho do mercado brasileiro (MENDES e ATTUCH, 2004, p. 68-9).

A diversificação de riscos é uma das causas apontadas por Douglas e Craig (1989) para o início da atividade internacional. Ter o governo brasileiro como principal cliente não era considerado seguro pela empresa, em razão da instabilidade econômica. A percepção era a de que "todo o país vive ciclos econômicos distintos, com períodos de restrições e abundância de investimentos. Mesmo no auge do milagre econômico, a Mendes já prospectava oportunidades fora do Brasil”' (MENDES e ATTUCH, 2004, p. 118).

No final dos anos 70, a empresa já havia conquistado um expressivo número de contratos no exterior, o que motivou a projeção de um cenário no qual $80 \%$ de suas receitas poderiam vir de outros países (fato encontrado, atualmente, na Norberto Odebrecht). A atitude era considerada prudente, pois a inadimplência estatal começava a acontecer no mercado brasileiro. Em fevereiro de 1981, o Jornal do Brasil, a esse respeito, estampou a manchete: “Governo deve Cr\$ 8 bilhões à Construtora Mendes Jr.”.

Depois de obter experiência no mercado latino-americano, a Mendes Júnior avançou em direção ao continente africano, "considerado estratégico pelo Itamarati como um mercado potencial para exportação de manufaturados e de serviços" (MENDES e ATTUCH, 2004, p. 121). "Incentivos governamentais", presentes nessa escolha, são citados por Douglas e Craig (1989) como um dos fatores que impulsionam à atividade internacional.

Em relação à forma de entrada, em sua entrevista, o diretor executivo explicou que a empresa procurou estabelecer parcerias com grandes empresas para a realização de projetos no exterior. Foram alianças consideradas estratégicas, porque agregaram tecnologia e desenvolvimento, além de contribuírem para o reconhecimento da Mendes na comunidade internacional. No final dos anos de 60, a empresa colheu “as primeiras vitórias comerciais na Argélia e, logo no início da década de 1970, na Mauritânia” (MENDES e ATTUCH, 2004, p. 121). Nesse período, o presidente da empresa já vivia a expectativa de vir a realizar obras bilionárias no Iraque. A construção da rodovia na Mauritânia foi considerada um marco na história da empresa, em razão de seu porte e dos desafios envolvidos.

Revista Ibero-Americana de Estratégia - RIAE, São Paulo, v. 11, n. 2, p. 281-307, mai./ago. 2012. 
$\mathrm{Na}$ década de 1970, o Iraque despontou como um país de grande riqueza e possibilidades comerciais. $\mathrm{O}$ "enriquecimento repentino dos países árabes já era uma grande razão para que uma empresa como a Mendes Júnior passasse a olhar com maior atenção para o Oriente Médio. Afinal, era para lá que o dinheiro corria" (MENDES e ATTUCH, 2004, p. 154). Além dos recursos abundantes para investimentos, fatores políticos e religiosos favoreceram a escolha pelo Iraque, dentre os países árabes. Outro aspecto também foi importante na definição do país: a questão da reciprocidade.

\footnotetext{
No início dos anos 70, a Petrobras [...] havia descoberto o campo de Majnoon, um dos maiores do mundo, [...]. Mas, como a exploração foi nacionalizada no Iraque, a estatal brasileira não pôde extrair o petróleo. Em compensação, o mercado iraquiano foi aberto à venda de produtos e serviços brasileiros, como a engenharia de construção pesada da Mendes Júnior (MENDES e ATTUCH, 2004, p. 156).
}

Em outubro de 1978, a construtora conquistou o contrato para a construção da ferrovia BagdáAkashat, com 553 quilômetros de extensão e orçamento de US\$ 1,2 bilhão. "Graças a ele, a Mendes Júnior figurou [...], de 1979 a 1982, como uma das quinze maiores empresas de construção pesada do mundo no ranking da Engineering News Record)" (MENDES e ATTUCH, 2004, p. 164).

Desenvolver uma obra de tamanha envergadura exigiu que a empresa alcançasse patamares até então inexistentes em sua trajetória. Engenheiros e profissionais de outras organizações foram recrutados para que a construtora conseguisse massa crítica suficiente para o intento. O modelo adotado foi o de trabalhar com grande equipe de brasileiros no exterior, dando-lhes condições de vida semelhantes às do Brasil. O aparato necessário para a construção desta infra-estrutura custou muito caro. Somente as casas préfabricadas, vindas dos Estados Unidos, custaram US\$ 50 milhões. No Iraque, a alimentação era subvencionada, o lazer era oferecido pela empresa e o combustível e o acesso à escola custavam muito pouco aos funcionários. Obviamente, manter tal estrutura trazia pesados comprometimentos financeiros à construtora.

Em 1981, a empresa assinou novo contrato da ordem de US\$ 333 milhões para construir um trecho de 128 quilômetros na Expressway, cujas especificações de qualidade eram superiores às exigidas nos EUA e na Europa. Em 1983, foi inaugurada a ferrovia Bagdá-Akashat e, em 1984, a empresa assumiu a obra do projeto Sifão, cujo objetivo era tornar agriculturável boa parte do território iraquiano; em razão das guerras, essa obra não foi concluída.

Em 1983, o Iraque já atrasava boa parte dos pagamentos, e a empresa cogitou a saída do país, mas optou por atender aos apelos do governo brasileiro para que lá permanecesse, fortalecendo os laços econômicos que uniam ambos os países. Em 1987, com mais de 400 milhões de dólares para receber, a construtora tomou a decisão de paralisar as obras.

Revista Ibero-Americana de Estratégia - RIAE, São Paulo, v. 11, n. 2, p. 281-307, mai./ago. 2012. 
Estratégia de Internacionalização de Empresas Brasileiras de Construção Pesada: Reflexões sobre a Trajetória e Resultados

Com o término da guerra, em 1988, acordos foram firmados envolvendo a empresa, o Banco do Brasil e o governo iraquiano, e em 1989 as obras foram reiniciadas. Em 2 de agosto de 1990, as forças iraquianas invadiram o Kwait dando início a outra guerra, o que mudaria novamente o rumo da história. As consequiências, desta vez, foram ainda mais devastadoras por causa do bloqueio econômico imposto ao país em 1990, o que obrigou a Mendes Júnior a abandonar o Iraque. A partir desse momento, a empresa passou a negociar com o governo brasileiro os pagamentos acertados com o Banco do Brasil. O não-acerto redundou, em 1995, na execução judicial da construtora e no começo de novo capítulo na história daquela que havia sido a principal empresa brasileira internacionalizada.

Em sua entrevista, o presidente da Mendes Júnior relatou que, ao deixar o Iraque, a empresa pretendia continuar atuando de forma intensa no mercado internacional, mas os problemas financeiros que sofreu impediram a viabilidade do projeto. No final dos anos de 80, no entanto, seus gestores já vislumbravam que seria necessário buscar mercados alternativos, em razão das dificuldades crescentes para garantir os pagamentos devidos pelo governo iraquiano. Para manter a atividade internacional, então, foi preciso reformular a orientação em termos de domínio de mercado, dirigindo esforços para a América Latina. O Chile foi escolhido como mercado principal pela Mendes Júnior, por conta de suas condições econômicas favoráveis.

Além do Chile, foram desenvolvidas obras em Honduras, Santo Domingo, Bolívia, Venezuela, República Dominicana e Peru. Segundo o diretor executivo de Tecnologia-Engenharia, que na ocasião era o diretor adjunto da Área Internacional, a estratégia era ampliar a participação no território latino americano, com concentração de esforços no Chile.

Nesse país, a construtora procurou, inicialmente, fazer um estudo detalhado do mercado e, a seguir, passou à escolha de um sócio chileno, por ser esta a condição básica para participar dos negócios locais. Durante os anos de 1989 a 2004, a empresa teve forte presença no país, executando obras de expressiva importância. Os resultados obtidos no Chile eram considerados positivos, a ponto de o presidente afirmar em seu livro, publicado em 2004, que o trabalho no Chile seria contínuo. "Não se trata de uma aposta de curto prazo", disse ele. No mesmo ano de publicação do livro, entretanto, a empresa encerrou suas atividades internacionais, como estratégia para melhorar seus resultados.

A manutenção das operações no Chile representou uma forma de permanecer viva no mercado internacional, especialmente a partir de 1995, quando a Mendes Júnior foi executada judicialmente pelo Banco do Brasil e pelo BNDES. Rentabilidade, portanto, não teria sido o único objetivo da internacionalização; a empresa pretendia ter um volume de atividades que garantisse a manutenção de seus técnicos e a preservação da boa imagem. Apesar dos esforços empreendidos pela Mendes Júnior para 
assegurar a presença internacional, ficou difícil sustentar estruturas em outros países, e a foi preciso recuar em termos de domínio de mercado, reduzindo sua atuação ao mercado brasileiro. Melhorar a liquidez passou a ser mais fundamental à continuidade da construtora.

A entrevista realizada com o presidente da empresa evidenciou que ele mantém um forte sentimento de revolta com a postura do governo na questão das dívidas contraídas no Iraque, cujos créditos nunca foram pagos por Saddam, atribuindo a ele as causas de seu insucesso no mercado internacional. A descapitalização da empresa foi muito expressiva e, apesar da tentativa de manter-se na América Latina, o retorno ao Brasil pareceu a melhor opção. Por outro lado, o entrevistado mostrou-se absolutamente certo de que havia colocado o governo em uma posição de "não escapamento". Ou seja, as vitórias obtidas nos tribunais obrigariam o pagamento dos valores devidos à empresa, algo que até então não aconteceu.

Em relação à gestão da construtora como um todo, a fala de seu presidente e o livro por ele publicado dão indícios de que desde que saiu do Iraque, em 1991, a empresa teria elegido como prioridade o recebimento dos valores devidos pelo governo, a tal ponto que isso teria consumido muito do seu vigor comercial. Enquanto aguarda pelo pagamento, a empresa segue trabalhando no Brasil com uma estrutura mais enxuta e centralizada. E seu presidente mantém planos para gerir os recursos que planeja receber.

Com a análise da Mendes Júnior, encerra-se o estudo do tema internacionalização. O quadro a seguir apresenta a síntese dos achados de pesquisa.

\begin{tabular}{|c|c|c|c|c|}
\hline SUBCATEGORIA & ANDRADE GUTIERREZ & MENDES JÚNIOR & NORBERTO ODEBRECHT & QUEIROZ GALVÃO \\
\hline internacionalização & $\begin{array}{l}\text { Início:1984, Congo } \\
\text { Motivo: alternativa à escassez } \\
\text { de obras no Brasil. } \\
\text { Resultados : positivos nas } \\
\text { primeiras obras (decisão de } \\
\text { apostar no potencial, na } \\
\text { cultura e na exposição } \\
\text { internacional). } \\
\text { Forma de entrada: varia, } \\
\text { depende do cliente. } \\
\text { Aprendizado: levou à } \\
\text { reorientação (equipe mínima } \\
\text { de brasileiros no exterior e } \\
\text { Zagope para Europa). } \\
\text { Planejamento estratégico: } \\
\text { foco atual na América Latina } \\
\text { (restrição). } \\
\text { Permanência para manter } \\
\text { estrutura. } \\
\text { Considera-se consolidada no } \\
\text { exterior. }\end{array}$ & $\begin{array}{l}\text { Início: } 1969, \text { Bolívia. } \\
\text { Vocação para } \\
\text { internacionalização na } \\
\text { origem. } \\
\text { Motivos para ida: } \\
\text { diversificar o risco. } \\
\text { África: incentivos } \\
\text { governamentais. } \\
\text { Forma de entrada: } \\
\text { parcerias com grandes } \\
\text { empresas. } \\
\text { 1978, Iraque: busca } \\
\text { de oportunidades, } \\
\text { facilidades políticas e } \\
\text { religiosas, } \\
\text { reciprocidade. } \\
\text { Final dos anos } 80: \\
\text { mercado alternativo à } \\
\text { crise (retorno à } \\
\text { América Latina). } \\
\text { Chile: foco de } 1989 \text { a } \\
\text { 2004. Entrada com }\end{array}$ & $\begin{array}{l}\text { Início: 1979, Peru e Chile; } \\
\text { 1980, África. } \\
\text { Motivo: resposta à diminuição } \\
\text { dos investimentos públicos. } \\
\text { Expansão contínua da presença } \\
\text { internacional: } \\
\text { 1990, foco Primeiro Mundo - } \\
\text { EUA para fortalecer } \\
\text { competitividade. } \\
\text { Forma de entrada: varia, } \\
\text { legislação local e } \\
\text { oportunidades. } \\
\text { Sempre com parceiros locais. } \\
\text { 2003: Oriente Médio. } \\
\text { Escolha de países: expectativa } \\
\text { de longo prazo - "50 anos". } \\
\text { Ter o profissional preparado } \\
\text { para decidir: "ter o homem". } \\
\text { Abordagem sistêmica da } \\
\text { estratégia. } \\
\text { Perpetuidade: composição com } \\
\text { a sociedade local, empresários- }\end{array}$ & $\begin{array}{l}\text { Início: 1984: Uruguai } \\
\text { (resultado negativo); } \\
\text { 1992: estruturação área } \\
\text { internacional; } \\
\text { 1994: Bolívia-retorno } \\
\text { atividade internacional } \\
\text { Motivos para ida: } \\
\text { competir com } \\
\text { multinacionais e manter } \\
\text { faturamento. } \\
\text { Foco: América Latina } \\
\text { Motivo escolha: } \\
\text { proximidade física e } \\
\text { cultural e contratos de } \\
\text { menor valor. } \\
\text { Forma de entrada: } \\
\text { consórcios com } \\
\text { empresas menores. } \\
\text { Processo de expansão: } \\
\text { conservador. } \\
\text { Futuro: expandir-se } \\
\text { para África, Oriente }\end{array}$ \\
\hline
\end{tabular}

Revista Ibero-Americana de Estratégia - RIAE, São Paulo, v. 11, n. 2, p. 281-307, mai./ago. 2012. 
Estratégia de Internacionalização de Empresas Brasileiras de Construção Pesada: Reflexões sobre a Trajetória e Resultados

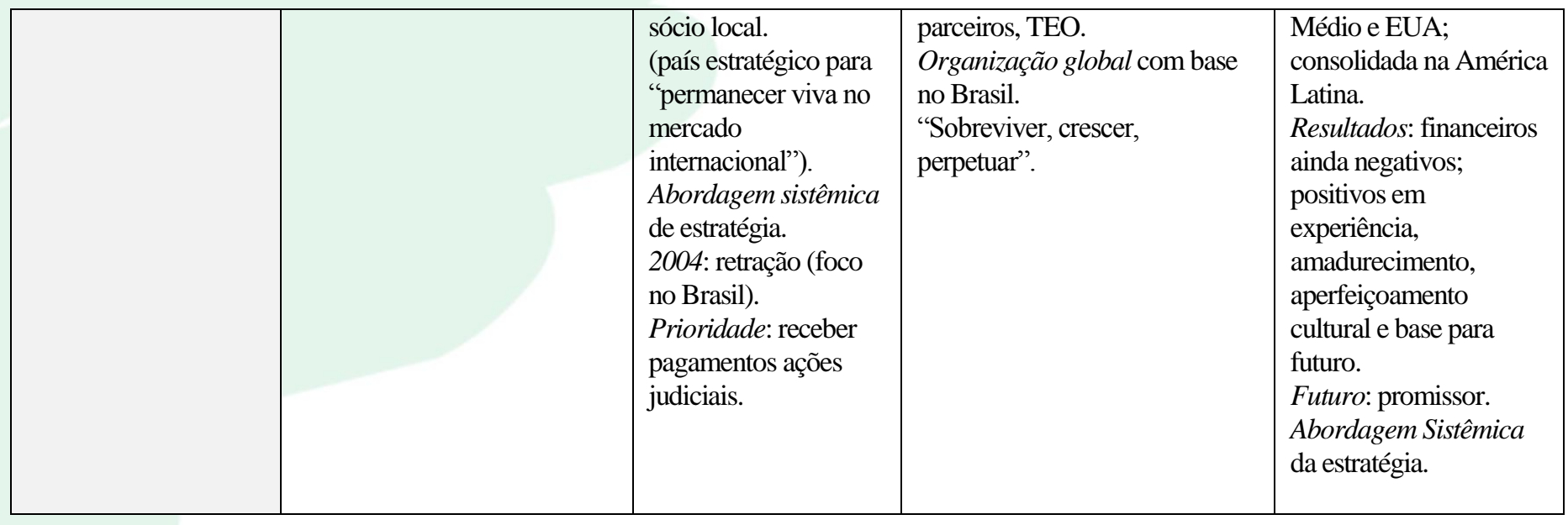

Quadro 2 - Internacionalização: síntese

\section{CONCLUSÃO}

Quanto à trajetória adotada para internacionalização, a análise dos quatro casos evidenciou semelhanças, com pequenas exceções. A ida para mercados externos ocorreu, prioritariamente, como estratégia diante da escassez de obras no Brasil. A Mendes Júnior, neste caso, foi a exceção, pois iniciou sua internacionalização em um período em que ainda era farto o mercado brasileiro de obras públicas.

A entrada em outros países, no caso de empresas de construção, dá-se pelo estabelecimento - obrigatório - de subsidiária local. A subsidiária precisa ser formalizada antes do início das obras. Para apresentar projetos e executar obras em outro país, as empresas precisam estar juridicamente constituídas no local. Para minimizar o desconhecimento relativo às condições de mercado, os casos estudados revelaram que as empresas trabalham, em regra, com parceiros locais. Sob esse aspecto, corrobora-se a tese de Nicolaud (1989) de que empresas de serviço não desfrutam das mesmas oportunidades de aprendizado a partir da experiência gradual, como acontece com produtores de bens, que podem experimentar processos de exportação indireta ou casual. Sob sua perspectiva, o comerciante de serviços não tem escolha senão lidar diretamente com o consumidor estrangeiro. Patterson e Cicic (1995) manifestaram semelhante visão ao afirmarem que empresas de serviço precisam estar em solo estrangeiro desde o primeiro dia de sua atividade internacional. A presença local é necessária, especialmente em situações nas quais o serviço oferecido seja customizado, caso típico dos serviços de engenharia e construção.

Revista Ibero-Americana de Estratégia - RIAE, São Paulo, v. 11, n. 2, p. 281-307, mai./ago. 2012. 
Outra semelhança dentre as empresas estudadas está no fato de que iniciaram a atividade internacional em ambientes nos quais a proximidade cultural era maior.

A respeito do estágio de internacionalização das empresas estudadas, observando a estrutura de Kotabe e Helsen (1998), foi elaborada a seguinte classificação:

- Andrade Gutierrez - orientação multinacional: mercado dividido em regiões;

- Mendes Júnior - orientação para o mercado doméstico;

- Norberto Odebrecht - orientação global;

- Queiroz Galvão - orientação internacional: orientação país-a-país;

Ainda que a construtora Queiroz Galvão tenha definido a América Latina como foco de sua atuação, pareceu que, efetivamente, ela trabalha em uma base de país-a-país. A Andrade Gutierrez, ao contrário, por ter mais tempo de internacionalização, redefiniu seu domínio de produto-mercado em uma base regional, estabelecendo a América Latina como mercado para a construtora. As demais regiões ficaram a cargo da Zagope, seu braço português.

Quanto às escolhas estratégicas e resultados decorrentes, os casos mostraram que a manutenção da atividade externa obedeceu a critérios outros, além da lucratividade. As construtoras entendem que estar atuando no exterior é importante para que alcancem patamares mais avançados de desenvolvimento, em termos tanto técnicos como gerenciais. A visibilidade internacional também é um fator importante, assim como a possibilidade de manter-se ativa. Neste caso, "estar entre as grandes do setor no mundo" parece explicar, em parte, a permanência, principalmente em momentos nos quais as empresas passaram por retração em seus níveis de lucratividade.

A manutenção de operações externas também foi explicada em função da necessidade de atualização constante, algo que só é conseguido por intermédio da execução contínua de obras, de diferentes perfis e exigências. Assim, a empresa acumula expertise em mercados internacionais, mantém seus níveis de faturamento e ainda garante sua capacidade de responder às demandas do mercado doméstico caso ocorram investimentos públicos em infra-estrutura.

Com tal quadro como referência, sugere-se a aplicação de semelhante estudo a outras indústrias prestadoras de serviço, de forma que se possa ampliar e consolidar o campo teórico que subsidia as discussões ora propostas na academia.

Revista Ibero-Americana de Estratégia - RIAE, São Paulo, v. 11, n. 2, p. 281-307, mai./ago. 2012. 
Estratégia de Internacionalização de Empresas Brasileiras de Construção Pesada: Reflexões sobre a Trajetória e Resultados

\section{REFERÊNCIAS}

Andrade Gutierrez. Relatório Anual 2004. Disponível em: < http://www.andradegutierrez.com.br/grupo.aspx?sub=grupo_relatorioanual> Acesso em 28/09/2007.

Bardin, L. Análise de conteúdo. 3.ed. Lisboa: Edições 70, 2004.

Dimaggio, P.J.; Powell, W.W. The iron cage revisited: institutional isomorphism and collective rationality in organizational fields. In: Powel, W.W; Dimaggio, P. (ed.s.). The new institutionalism in organizational analysis. Chicago: The University of Chicago Press, 1991.

Douglas, S. P.; Craig, C. S. Evolution of Global Marketing Strategy: scale, scope, and synergy. Columbia Journal of World Business, p.47-59, Fall 1989.

Dunning, J. H. The Ecletic Paradigm of International Production: a restatement and some possible extensions. Journal of International Business Studies, p.1-31, Spring 1988.

Dunning, J. H. The nature of transnational corporations and their activities. In: UNITED NATIONS. Transnational corporations and world development. London: International Thomson Business Press, 1996, p. 27-43.

Heil, O.P.; Day, G.S.; Reibstein, D.J. Enviando sinais aos concorrentes. In: Day, G. S. e Reibstein, D.J. A dinâmica da estratégia competitiva. Rio de Janeiro: Campus, 1999, p.284-299.

Johanson, J.; Vahlne, J. The mechanism of internationalization. International Marketing Review, v. 7, n.4, p. 11-24, 1990.

Kotabe, M. e Helsen, K. Global Marketing Management. New York: John Wiley \& Sons, 1998.

Lewin, A Y., Long, C. P. e Carroll, T. N. The coevolution of new organizational forms. Organization Science, v. 10, n. 5, p. 535-550, set/out 1999.

Li, J. Foreign entry and survival: effects of strategic choices on performance in international markets. Strategic Management Journal, v. 16, pp. 333-351, 1995.

Malhotra, N. K. Pesquisa de Marketing: uma orientação aplicada. 3.ed. Porto Alegre: Bookman, 2001.

Mata, J.; Portugal, P. Patterns of Entry, post-entry growth and survival. Small Business Economics, n. 22, p.283-298, 2004.

Revista Ibero-Americana de Estratégia - RIAE, São Paulo, v. 11, n. 2, p. 281-307, mai./ago. 2012. 
Mattar, F. N. Pesquisa de marketing: metodologia, planejamento. v.1. São Paulo: Atlas, 1997.

Melin, L. Internationalization as a strategy process. Strategic Management Journal, v. 13, pp.99118, 1992.

Mendes, M. e Attuch, L. Quebra de contrato: o pesadelo dos brasileiros. Belo Horizonte: Del Rey, 2004.

Nicolaud, B. Problems and strategies in the international marketing of services. European Journal of Marketing, v. 23, n. 6, p.55-66, 1989.

Odebrecht. Mensagem do Conselho: a relação entre as pessoas como fundamento da prestação de serviços. Odebrecht Informa, n. 20, ano XXXII, setembro/outubro 2005, p. 9.

Odebrecht, N. A história essencial. Odebrecht Informa On Line. Edição histórica, novembro de 2004. Disponível em: . Acesso em 25/03/2007.

Patterson, P.G. e CICIC, M. A typology of service firms in international markets: an empirical investigation. Journal of International Marketing, v. 3, n. 4, p.57-83, 1995.

Recebido: 30/03/2012

Aprovado: 17/05/2012

Revista Ibero-Americana de Estratégia - RIAE, São Paulo, v. 11, n. 2, p. 281-307, mai./ago. 2012. 